\title{
Author Correction: Spin-controlled generation of indistinguishable and distinguishable photons from silicon vacancy centres in silicon carbide
}

Naoya Morioka (1D, Charles Babin, Roland Nagy, Izel Gediz, Erik Hesselmeier (D), Di Liu (D), Matthew Joliffe, Matthias Niethammer, Durga Dasari, Vadim Vorobyov (D), Roman Kolesov, Rainer Stöhr, Jawad Ul-Hassan (D), Nguyen Tien Son (1), Takeshi Ohshima (1), Péter Udvarhelyi, Gergő Thiering (10, Adam Gali (1), Jörg Wrachtrup \& Florian Kaiser (D)

Correction to: Nature Communications https://doi.org/10.1038/s41467-020-16330-5, published online 20 May 2020.

The original version of this Article contained an error in Supplementary Eq. (8), and incorrectly read:

$$
V=\frac{1}{(1-\varepsilon)^{2}}\left[\left\{\left(\frac{\mathrm{SN}+1}{\mathrm{SN}}\right)^{2} \alpha_{2}+\frac{2 \alpha_{1}}{\mathrm{SN}}\right\}-\left(1-V_{0}\right)\left\{\left(\frac{\mathrm{SN}+1}{\mathrm{SN}}\right)^{2} \alpha_{1}+\frac{2 \alpha_{2}}{\mathrm{SN}}\right\}\right]
$$

The correct form of Supplementary Eq. (8) is:

$$
V=\frac{1}{(1-\varepsilon)^{2}}\left[\left\{\left(\frac{\mathrm{SN}+1}{\mathrm{SN}}\right)^{2} \alpha_{2}+\frac{4 \alpha_{1}}{\mathrm{SN}}\right\}-\left(1-V_{0}\right)\left\{\left(\frac{\mathrm{SN}+1}{\mathrm{SN}}\right)^{2} \alpha_{1}+\frac{2 \alpha_{2}}{\mathrm{SN}}\right\}\right]
$$

The original version of this Article contained an error in Supplementary Eq. (11), and incorrectly read:

$$
V=\frac{1}{(1-\varepsilon)^{2} \beta_{\text {jitter }}}\left[\left\{\left(\frac{\mathrm{SN}+1}{\mathrm{SN}}\right)^{2} \alpha_{2}+\frac{2 \alpha_{1}}{\mathrm{SN}}\right\}-\left(1-V_{0}\right)\left\{\left(\frac{\mathrm{SN}+1}{\mathrm{SN}}\right)^{2} \alpha_{1}+\frac{2 \alpha_{2}}{\mathrm{SN}}\right\}\right]
$$

The correct form of Supplementary Eq. (11) is:

$$
V=\frac{1}{(1-\varepsilon)^{2} \beta_{\text {jitter }}}\left[\left\{\left(\frac{\mathrm{SN}+1}{\mathrm{SN}}\right)^{2} \alpha_{2}+\frac{4 \alpha_{1}}{\mathrm{SN}}\right\}-\left(1-V_{0}\right)\left\{\left(\frac{\mathrm{SN}+1}{\mathrm{SN}}\right)^{2} \alpha_{1}+\frac{2 \alpha_{2}}{\mathrm{SN}}\right\}\right]
$$

As a result of the errors identified in Supplementary Eqs. (8) and (11), the original version of this Article contained an error in Figs. 3 and 4, and Supplementary Fig. 4. 
The correct version of Fig. 3 is:

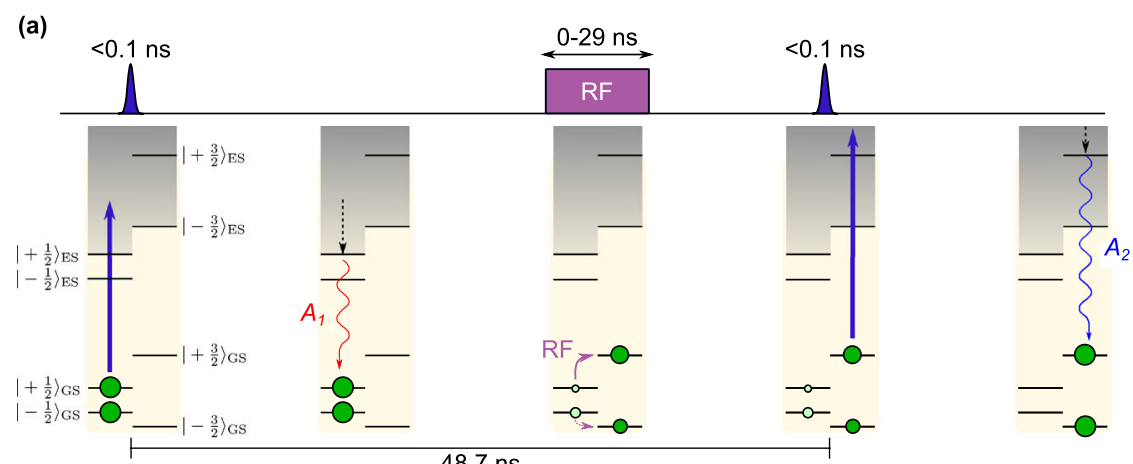

(b)

(d)
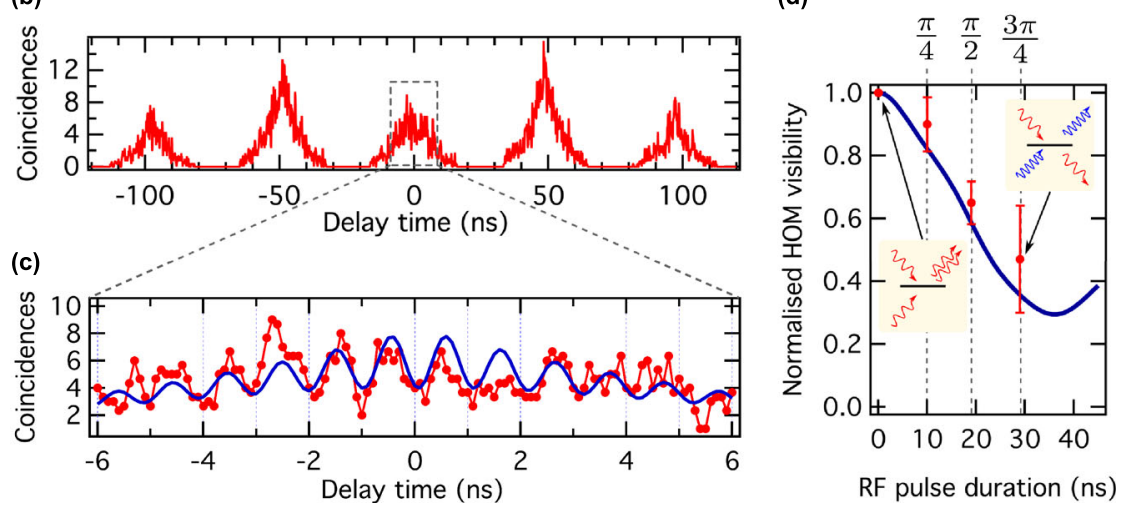

Which replaces the previous incorrect version.

The correct version of Fig. 4 is:

(a)

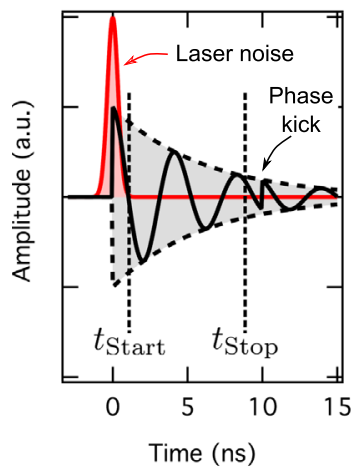

(b)

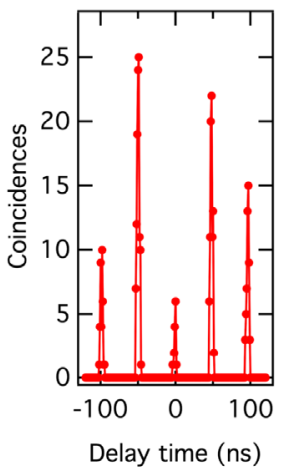

(c)

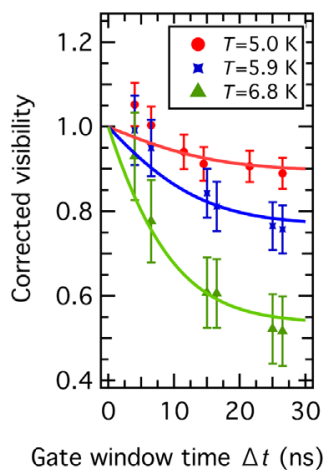

(d)

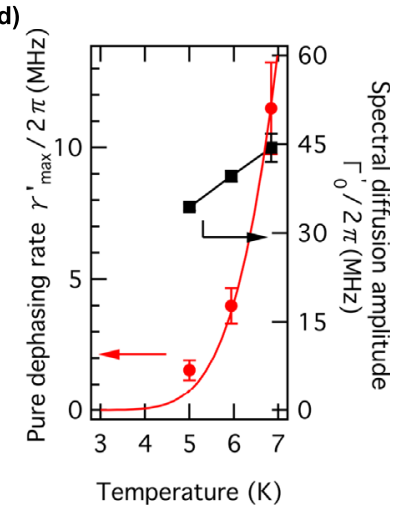

Which replaces the previous incorrect version. 
The correct version of Supplementary Fig. 4 is:

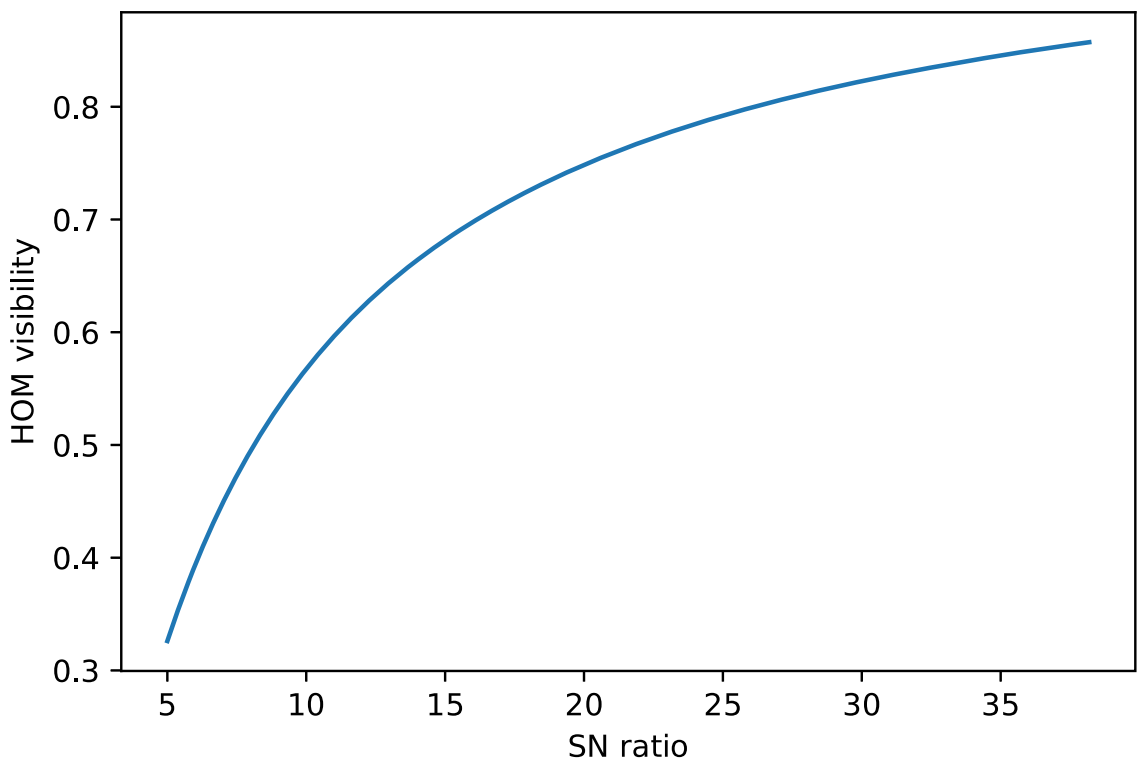

which replaces the previous incorrect version.

As a result of the errors identified in Supplementary Eqs. (8) and (11), the original version of the Supplementary Information contained an error in Supplementary Table 1. The correct version of Supplementary Table 1 is:

\begin{tabular}{|c|c|c|c|c|c|}
\hline \multirow[b]{2}{*}{$\begin{array}{l}\text { Temperature } \\
\text { [K] }\end{array}$} & \multirow[b]{2}{*}{$\begin{array}{l}\text { PLE linewidth } \\
{[\mathrm{MHz}]}\end{array}$} & \multicolumn{2}{|c|}{ Pure dephasing limited } & \multicolumn{2}{|c|}{$\underline{\text { Spectral diffusion limited }}$} \\
\hline & & $\begin{array}{l}\gamma_{\max }^{\prime} / 2 \pi \\
{[\mathrm{MHz}]}\end{array}$ & $\begin{array}{l}\Gamma_{\mathbf{0}}^{\prime} / \mathbf{2} \pi \\
{[\mathbf{M H z}]}\end{array}$ & $\begin{array}{l}\Gamma_{0, \max }^{\prime} / 2 \pi \\
{[\mathrm{MHz}]}\end{array}$ & $\begin{array}{l}\tau_{c, \min } \\
{[\mathrm{ns}]}\end{array}$ \\
\hline 5.0 & $62.4 \pm 0.4$ & $1.5 \pm 0.4$ & $34.4 \pm 0.5$ & $35.9 \pm 0.4$ & $109 \pm 8$ \\
\hline 5.9 & $70.1 \pm 0.3$ & $4.0 \pm 0.7$ & $39.6 \pm 0.7$ & $43.6 \pm 0.3$ & $81 \pm 6$ \\
\hline 6.8 & $82.4 \pm 0.3$ & $11.5 \pm 1.7$ & $44.4 \pm 1.8$ & $55.9 \pm 0.3$ & $51 \pm 6$ \\
\hline
\end{tabular}

,which replaces the previous incorrect version.

As a result of the errors identified in Supplementary Eqs. (8) and (11), the original version of the Article contained the errors listed in the second column of the table below.

The corrected values (listed in the third column) have been corrected both in the PDF and HTML versions of the Article.

\begin{tabular}{|c|c|c|}
\hline Position in the Article & Wrong items & Corrected items \\
\hline Introduction & $\begin{array}{l}\text {... a naturally stable spin-photonic interface at temperatures up } \\
\text { to } 6.6 \mathrm{~K}\end{array}$ & $\begin{array}{l}\text {... a naturally stable spin-photonic interface at temperatures up } \\
\text { to } 6.9 \mathrm{~K}\end{array}$ \\
\hline $\begin{array}{l}\text { Results, Spin-controlled distinguishable photon } \\
\text { generation }\end{array}$ & $\begin{array}{l}V_{\max }=0.65 \pm 0.05 \\
V_{\text {norm }, \pi / 2}=\frac{V_{\text {measured }}}{V_{\text {digx }}}=0.61 \pm 0.10 \\
V_{\text {norm }, \pi / 4}=0.89 \\
V_{\text {norm } 3 \pi / 4}=0.37 \pm 0.26\end{array}$ & $\begin{array}{l}V_{\max }=0.73 \pm 0.05 \\
V_{\text {norm }, \pi / 2}=\frac{V_{\text {measured }}}{V_{\text {gax }}}=0.65 \pm 0.07 \\
V_{\text {norm }, \pi / 4}=0.90 \pm 0.09 \\
V_{\text {norm }, 3 \pi / 4}=0.47 \pm 0.17\end{array}$ \\
\hline Results, Temperature stability of spin-photonic & $A=2 \pi \cdot(365 \pm 36) \mathrm{MHz}(\mathrm{meV})^{-3}$ & $A=2 \pi \cdot(237 \pm 12) \mathrm{MHz}(\mathrm{meV})^{-3}$ \\
\hline properties & $T_{\text {crit }}>6.6 \mathrm{~K}$ & $T_{\text {crit }}>6.9 \mathrm{~K}$ \\
\hline Figure $3 c$, caption & $\begin{array}{l}\ldots \text { the fringe pattern with the expected modulation at } \\
0.966 \pm 0.007 \mathrm{GHz}\end{array}$ & $\begin{array}{l}\ldots \text { the fringe pattern with the expected modulation at } \\
0.965 \pm 0.006 \mathrm{GHz}\end{array}$ \\
\hline Figure $4 \mathrm{~b}$, caption & $\ldots$ the theoretical expectation $(0.86 \pm 0.01)$ & $\ldots$ the theoretical expectation $(0.80 \pm 0.01)$ \\
\hline
\end{tabular}

As a result of the errors identified in Supplementary Eqs. (8) and (11), the original version of the Supplementary Information contained the errors listed in the second column of the table below. 
The HTML has been updated to include a corrected version of the Supplementary Information.

\begin{tabular}{|c|c|c|}
\hline Position in Supplementary Information & Wrong items & Corrected items \\
\hline $\begin{array}{l}\text { Supplementary Note } 3 \text {, page } 7 \\
\text { Supplementary Note } 3 \text {, page } 8 \\
\text { Supplementary Note } 4 \text {, page } 11 \text {, Supplementary Fig. } 6 \text {, caption } \\
\text { Supplementary Note } 7 \text {, page } 17\end{array}$ & $\begin{array}{l}\ldots \text { the maximum achievable } \mathrm{HOM} \text { visibility is upper bound at } 87 \% \\
\ldots \text { the maximum achievable HOM visibility is upper bound at }(86 \pm 1) \% \\
V(\mathrm{RF} \text { before sequence })=0.65 \pm 0.05 \\
\gamma=(119 \pm 5) \mathrm{MHz} \\
\left(1-V_{\text {norm }}\right)=0.39 \pm 0.1 \\
\frac{c_{2}}{c_{1}}=\frac{V_{\text {nom }}}{1-V_{\text {m }}}=1.55 \pm 0.47 \\
c_{3} / c_{1}=0.60 \pm 0.12 \\
c_{1}=739 \pm 11 \\
\delta \nu=(0.966 \pm 0.007) \mathrm{GHz} \\
\sigma_{\text {det }}=(0.16 \pm 0.02) \mathrm{ns}\end{array}$ & $\begin{array}{l}\ldots \text { the maximum achievable HOM visibility is upper bound at } 81 \% \\
\ldots \text { the maximum achievable } \mathrm{HOM} \text { visibility is upper bound at }(80 \pm 1) \% \\
V(\mathrm{RF} \text { before sequence })=0.73 \pm 0.05 \\
\gamma=(84 \pm 4) \mathrm{MHz} \\
\left(1-V_{\text {norm }}\right)=0.37 \pm 0.06 \\
\frac{c_{2}}{c_{1}}=\frac{V_{\text {norm }}}{1-V_{\text {m }}}=1.68 \pm 0.45 \\
c_{3} / c_{1}=0.63 \pm 0.11 \\
c_{1}=753 \pm 12 \\
\delta \nu=(0.965 \pm 0.006) \mathrm{GHz} \\
\sigma_{\text {det }}=(0.17 \pm 0.02) \mathrm{ns}\end{array}$ \\
\hline
\end{tabular}

The Supplementary Information contained a typographical error in the second sentence of the caption of Supplementary Fig. 6, and incorrectly read:

"Time gating settings are $t_{\text {Start }}=2 \mathrm{~ns}$ and $\Delta t=16.5 \mathrm{ns".}$

The correct sentence is:

“Time gating settings are $t_{\text {Start }}=2 \mathrm{~ns}$ and $\Delta t=16 \mathrm{ns".}$

The HTML has been updated to include a corrected version of the Supplementary Information. The correct version of the Supplementary Information can be found associated with this Correction.

Published online: 07 October 2021

\section{Additional information}

Supplementary information The online version contains supplementary material available at https://doi.org/10.1038/s41467-021-25869-w.

Open Access This article is licensed under a Creative Commons Attribution 4.0 International License, which permits use, sharing, adaptation, distribution and reproduction in any medium or format, as long as you give appropriate credit to the original author(s) and the source, provide a link to the Creative Commons license, and indicate if changes were made. The images or other third party material in this article are included in the article's Creative Commons license, unless indicated otherwise in a credit line to the material. If material is not included in the article's Creative Commons license and your intended use is not permitted by statutory regulation or exceeds the permitted use, you will need to obtain permission directly from the copyright holder. To view a copy of this license, visit http://creativecommons.org/licenses/by/4.0/.
}

(C) The Author(s) 2021 